\title{
6) Отчеты.
}

Заключение: В данной программе вы можете создавать отчеты на поставку. В отчеты включена вся необходимая информация о поставленном и расходуемом грузе, а так же всю информацию о грузе.

$$
* * *
$$

1. Диго С.М. "Проектирование и использования баз данных". - М.: Финансы и статистика, 2005.212c.

2. Когловский М.Р. "Технология баз данных на персональных ЭВМ". - М.: 'Финансы и статистика', 2002.- 316c.

3. Кандзюба С.П. Delphi. Базы данных и приложения. - М.: ДиаСофт, 2005.- 232c.

4. Конноли Т., Бег К.А. Базы данных. Проектирование, реализация и сопровождение. Теория и практика. 3-е издание. - СПб.: Вильямс, 2003.- 223с.

5. Фаронов В.В. Программирование баз данных в Delphi 6. - СПб.: Питер, 2002.- 434c.

6. Фаронов B.В. Система программирования Delphi. - СПб.: БХВ-Петербург, 2003.- 432c.

7. Культин Н.Б. Программирование баз данных в Delphi. - М.: Мир, 2006.- 323c.

\section{Роговая Л.А. \\ Эвристический алгоритм решения задачи календарного планирования работ команд специалистов}

Воронежский государственный технический университет (Россия, Воронеж)

doi:10.18411/spc-22-11-2017-09

idsp: 000001:spc-22-11-2017-09

Задача календарного планирования илизадача распределения ресурсов(трудовых, финансовых, материально-технических и т.д.) в управлении проектами относится к сложным задачам дискретной оптимизации.

Особый интерес представляет задачараспределения команд специалистов по работам проекта, для решения которой применимы эвристические алгоритмы, основанные на правилах приоритета работ.

В управлении проектами для решения задач распределения ресурсовшироко применяются эвристические алгоритмы, основанные на некоторых разумных правилах, не гарантирующих получение оптимального решения (эвристических правилах) $[1,2,3$, 4].

В литературе выделяют три основных правила распределения ресурсов по работам[5]:

1. по степени критичности работ (в первую очередь начинаются работы с минимальным поздним сроком начала);

2. по минимальной продолжительности работ (в первую очередь начинаются работы, имеющие минимальную продолжительность);

3. по минимальному сроку окончания.

Рассмотрим задачу назначения команд специалистов при запрещении прерывания работ. При запрещении прерывания работ задача становится сложной (NPтрудной) задачей дискретной оптимизации. Для ее решения применяется эвристический алгоритм, основанный на правиле приоритета, согласно которому в первую очередь выполняются критические работы, то есть работы с наибольшей продолжительностью $\tau_{i}$.

Алгоритм решения задачи реализуется в два шага:

1 шаг. В начальный момент времени $\mathrm{t}=0$ назначаем команды в очередности убывания продолжительностей соответствующих работ до получения максимального набора.

Максимальным набором называется набор, к которому нельзя добавить ни одной команды, не нарушив ограничения (1): 


$$
\sum_{i \in Q} \alpha_{i j} \leq N_{j}, j=\overline{1, m}
$$

где ${ }^{\alpha_{i j}}$ - параметры набора,

$N_{j}$-число специалистов ј-го типа,

$\mathrm{Q}$ - набор команд.

2 шаг. В момент окончания какой-либо работы назначаем команды также в очередности убывания продолжительностей еще невыполненных работ.

Пример. Имеются шесть работ, и соответственно шесть команд, данные о которых приведены в таблице 1.

Имеются также пять типов специалистов, причемв наборе команд специалистов каждого типа не больше 2.

Таблица 1

\begin{tabular}{|c|c|c|c|c|c|c|}
\hline $\mathrm{i}$ & 1 & 2 & 3 & 4 & 5 & $\tau_{j}$ \\
\hline 1 & 1 & 1 & 0 & 1 & 0 & 15 \\
\hline 2 & 0 & 1 & 1 & 0 & 1 & 12 \\
\hline 3 & 1 & 0 & 0 & 1 & 0 & 10 \\
\hline 4 & 0 & 1 & 1 & 0 & 0 & 8 \\
\hline 5 & 0 & 0 & 1 & 1 & 1 & 4 \\
\hline 6 & 0 & 1 & 0 & 1 & 1 & 2 \\
\hline
\end{tabular}

В строках таблицы приведены команды для каждой работы, а в столбцах занятость специалистов каждого типа.

1 шаг. $\mathrm{B}$ момент $\mathrm{t}=0$ начинаем работы 1,2 и 3 , которые образуют максимальный набор.

2 шаг. В момент $\mathrm{t}=10$ заканчивается работа 3. Начинаем работу 5. Работу 4 или 6 начать не можем, поскольку наборы $(1,2,4)$ и $(1,2,6)$ не допустимы.

3 шаг. В момент $\mathrm{t}=12$ заканчивается работа 2 . Начинаем работу 4 , поскольку набор $(1,5,6)$ не допустим.

4 шаг. В момент $\mathrm{t}=14$ заканчивается работа 5 .

5 шаг. В момент $\mathrm{t}=15$ заканчивается работа 1 . Начинаем работу 6 , поскольку набор $(1,5,6)$ допустим.

6 шаг. В момент $\mathrm{t}=17$ заканчивается работа 6 .

7 шаг. В момент $\mathrm{t}=20$ заканчивается работа 4 .

Продолжительность выполнения всех работ равна 20.

Разрешив прерывание работ, можно получить оценку снизу, рассмотрев возможные максимальные наборы команд и решив задачу линейного программирования.

$$
* * *
$$

1. Бурков В.Н. Эвристический подход к решению динамических задач распределения ресурсов / В.Н.Бурков, С.Е. Ловецкий // Автоматика и телемеханика. -1996. - № 5. - С. 119-129.

2. Алферов В.И. Эвристические алгоритмы распределения ресурсов /В.И.Алферов, В.Н. Бурков, А.Е.Кравцов, Ю.А.Карпов // Вестник Воронежского государственного технического университета. 2009. - T. 5. - № 12. - С. 176-179.

3. Баркалов С.А. Эвристические алгоритмы распределения ресурсов / С.А.Баркалов, А.И.Котенко,Ю.П. Лихотин // Системы управления и информационные технологии. - 2004. - Т. 17. - № 5. C. 4-13.

4. Россихина, Л.В. Постановка задачи формирования календарного плана с взаимозависимыми мероприятиями и алгоритм ее решения / Л.В. Россихина // Вестник Воронеж.ин-та МВД России. 2014. - № 3. - С. 81-89.

5. Потапенко А.М. Эвристические методы распределения ресурсов при управлении проектами / дис...канд. техн. наук : 05.13.10 / Потапенко Анатолий Михайлович. - Воронеж: ВГАСУ, 2004. $218 \mathrm{c}$. 